\title{
Duque Cornejo en Colombia: el San Joaquín de Popayán y sus copias
}

\author{
Duque Cornejo in Colombia: The St Joachim of Popayán \\ and its Copies
}

\author{
Manuel García Luque ${ }^{1}$ \\ Universidad de Sevilla
}

Resumen: El artículo plantea la atribución al escultor sevillano Pedro Duque Cornejo (1678-1757) de una escultura de San Joaquín conservada en la iglesia del Carmen de Popayán (Colombia). Para ello, se reconstruye el contexto creativo de la obra, se proponen algunas hipótesis sobre sus potenciales comitentes y se evalúa su repercusión en el medio local, donde fue copiada hasta en tres ocasiones. Su caso resulta significativo para el estudio del comercio de escultura entre España y América durante el siglo XVIII, y prueba que el taller de Duque Cornejo tuvo una proyección americana desconocida hasta la fecha.

Palabras clave: Pedro Duque Cornejo; San Joaquín; Popayán (Colombia); Sevilla; escultura.

\begin{abstract}
This paper proposes the attribution to the Sevillian sculptor Pedro Duque Cornejo (1678-1757) of a sculpture representing St Joachim, preserved in the church of Carmen in Popayán, Colombia. For this, it is reconstructed the creative context of the work, posing some hypotheses about its potential clients and evaluating its impact on the city, where it was copied up to three times. Its case is significant for the study of the sculpture trade between Spain and America during the eighteenth century, proving that Duque Cornejo's workshop had an American expansion, unknown to date.
\end{abstract}

Key words: Pedro Duque Cornejo; St Joachim; Popayán (Colombia); Seville; sculpture.

\footnotetext{
1 (ㄱ) https://orcid.org/0000-9795-5679
}

(C) 2021 Philostrato. Revista de Historia y Arte 


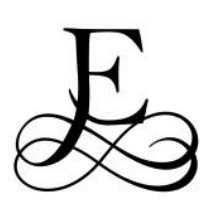

s bien conocido que la elección de Sevilla como puerto de Indias constituyó un factor decisivo que permitió que la escultura sevillana se proyectara hacia el Nuevo Mundo². El proceso de conquista, evangelización y aculturación del continente americano implicó la exportación a gran escala de pinturas, esculturas, retablos y toda suerte de mercaderías artísticas para atender las necesidades litúrgicas, devocionales y de representación de la naciente América virreinal. Este crecimiento espectacular de la demanda situó a los escultores sevillanos en una posición privilegiada respecto a los que trabajaban en otros centros de la península, gracias al monopolio comercial que disfrutaba el puerto de Sevilla con América. Desde el puerto hispalense se embarcaron hacia el Nuevo Mundo innumerables imágenes realizadas en los más diversos materiales: desde la tradicional madera policromada, pasando por el barro y el peltre -soportes económicos que permitían la fabricación seriada-, hasta materias ricas como el marfil, el alabastro o incluso el azabache, que no necesariamente habían sido manufacturadas en Sevilla ${ }^{3}$.

Aunque este flujo comercial se dirigió a ambos virreinatos, Angulo ya advirtió que muchas de las piezas elaboradas por los obradores sevillanos fueron remitidas hacia América del Sur ${ }^{4}$. Ya desde el segundo tercio del siglo XVI se documentan envíos de obras de autores como Jorge Fernández Alemán (†1535) o Roque Balduque (ca.1500-1561), y el fenómeno alcanzó su punto álgido entre 1580 y 1650 , cuando aparecen involucrados en el comercio americano artistas de la talla de Juan Bautista Vázquez el Viejo (ca.1510-1588), Juan Martínez Montañés (1568-1649), Francisco de Ocampo (1579-1639) o Juan de Mesa (1583-1627). A veces estos envíos

\footnotetext{
2 Esta investigación se enmarca en el proyecto "Circulación de la imagen en la geografía artística de la Edad Moderna Hispánica" (PD2020-112808GB-100), financiado por el Ministerio de Ciencia e Innovación. El trabajo no podría haber visto la luz sin la desinteresada ayuda brindada por Laura Liliana Vargas Murcia, Patrick Lenaghan y la corporación "Proyecto Patrimonio".

3 La bibliografía sobre la presencia de escultura sevillana en América es abundante, aunque merecen destacarse algunos trabajos clásicos como los de Diego Angulo Íñiguez, "Dos Menas en Méjico. Esculturas sevillanas en América", Archivo Español de Arte y Arqueología, 31 (1935), pp. 131-152; E. Harth-Terré, "Una escultura de Martínez Montañés en Lima", Cuadernos Hispanoamericanos, 152-153 (1962), pp. 261-271; Enrique Marco Dorta, "Esculturas sevillanas en Colombia y Venezuela", Archivo Español de Arte, 206, (1979), pp. 170-173; Jorge Bernales Ballesteros, "Escultura montañesina en América", Anuario de Estudios Americanos, 38, (1981), pp. 499-566; Margarita Estella Marcos, Juan Bautista Vázquez el Viejo en Castilla y América, (Madrid: CSIC, 1990); M. Estella Marcos, "Sobre escultura española en América y Filipinas y algunos otros temas", en Relaciones artísticas entre España y América, (Madrid: CSIC, 1990), pp. 73-106. Entre los trabajos recientes, véanse Iván Antonio Quintana Echeverría, "Notas sobre el comercio artístico entre Sevilla y América en 1586", Anales del Museo de América, 8, (2000), pp. 103-110; Jesús M. Palomero Páramo, "El mercado escultórico entre Sevilla y Nueva España durante el primer cuarto del siglo XVII. Marchantes de la carrera de Indias, obras de plomo exportadas y ensambladores de retablos que pasan a México", en Escultura. Museo Nacional del Virreinato, coords. M. Fernández Félix y M. Montiel Figueiras, (México: Museo Nacional del Virreinato, 2007), vol. 1, pp. 107-118; Lázaro Gila Medina y Francisco J. Herrera García, "Escultores y esculturas en el Reino de la Nueva Granada (Colombia)", en La escultura del primer Naturalismo en Andalucía e Hispanoamérica (1580-1625), coord. Lázaro Gila Medina, (Madrid: Arco/Libros, 2010), pp. 501-562; José María Sánchez Sánchez, "Los obradores artísticos sevillanos del siglo XVI: adaptaciones y cambios para satisfacer los encargos del mercado americano", Anales del Instituto de Investigaciones Estéticas, 103, (2013), pp. 177-196; Jesús Andrés Aponte Pareja, Escultura en el Nuevo Reino de Granada. Siglos XVI-XVII, (Bogotá: J. Aponte, 2015); Adrián Contreras Guerrero, Escultura en Colombia: focos productores y circulación de obras (siglos XVI-XVIII), (Granada: Universidad de Granada, 2019).

${ }^{4}$ Angulo, "Dos Menas en Méjico", p. 138.
} 
respondían a encargos previamente acordados con comitentes americanos, en otras ocasiones surgían por iniciativa de los religiosos que embarcaban a Indias $y$, por supuesto, tampoco faltaban las remesas de esculturas producidas en serie y vendidas al por mayor, que se confiaban a mercaderes, capitanes de barco o pasajeros con la esperanza de hallar comprador en destino, pese a los evidentes riesgos que entrañaba el negocio.

No resulta fácil determinar cómo evolucionó este tráfico artístico a lo largo de los siglos XVII y XVIII, pues las fuentes de archivo se vuelven menos elocuentes con el paso del tiempo. Estas limitaciones metodológicas resultan palmarias en el estudio de los protocolos notariales, ya que el descenso de noticias sobre el comercio de esculturas con América que se constata a partir de la segunda mitad del XVII coincide con un periodo en el que también disminuye drásticamente la protocolización de contratos y cartas de pago de obras realizadas para el mercado interior ${ }^{5}$, situación que se acentúa durante la siguiente centuria, cuando solo pasaban ante el escribano los proyectos de gran envergadura como los retablos. Esta laguna documental tal vez podría contrarrestarse con un análisis sistemático de los registros de mercancías de la Casa de Contratación, que podría arrojar datos acerca del volumen de obras remitidas, de sus tamaños, materiales e iconografías, aunque no así de sus autores ${ }^{6}$.

De todos modos, esta escasez de noticias también delata un probable cambio de ciclo en el comercio de la escultura. No cabe duda de que la emigración de artistas europeos hacia el Nuevo Mundo y el progresivo desarrollo de los talleres americanos redujo la demanda de obras a la metrópoli, lo que lógicamente repercutió en la dinámica del mercado escultórico y sus sistemas de producción. El declive también se vería acelerado por una serie de cambios operados en la carrera de Indias, pues la paulatina pérdida de calado del río Guadalquivir motivó que en 1679 la flota se trasladara al puerto de Cádiz, y el golpe de gracia llegaría en 1717 con el traslado de la Casa de Contratación a esta última ciudad.

A pesar de que la coyuntura resultaba menos favorable, es posible afirmar que todavía en el siglo XVIII la escultura producida en Sevilla y en otros centros de la España peninsular llegó hasta América. Así lo corrobora el ejemplo del San Joaquín de Pedro Laboria que se conserva en la iglesia de San Francisco de Bogotá, en Colombia. Un cronista contemporáneo, José Antonio Vargas Jurado, asegura que la obra fue realizada en Cádiz en 1729 por encargo del capitán Cristóbal López de Vergara, quien poco después marcharía al virreinato de Nueva Granada, Ilevando consigo la imagen del santo junto a unas arañas de bronce y unos espejos comprados en la

\footnotetext{
${ }^{5}$ Una excepción la constituye el poder firmado por el escultor Alonso Martínez en 1650 para cobrar en Tierra Firme diversas mercaderías, seguramente esculturas. Véase Enrique Respeto Martín, Artífices gaditanos del siglo XVII, Col. Documentos para la historia del Arte en Andalucía, t. X, (Sevilla: Universidad de Sevilla-Laboratorio de Arte, 1946), p. 57.

${ }^{6}$ Ejemplar en este sentido resulta el trabajo de Quintana Echeverría, "Notas sobre el comercio artístico", p. 105.
} 
misma ciudad7. Es posible que el escultor acompañara al capitán en este viaje, pues se ha documentado su paso por Santa Fe de Bogotá entre los años treinta y cuarenta del XVIII ${ }^{8}$.

En este siglo, la próspera ciudad de Popayán también se convirtió en un destino habitual de muchas esculturas de importación, que en ocasiones eran adquiridas aprovechando el viaje a Europa de algunos religiosos ${ }^{9}$. Esto fue lo que ocurrió con la Virgen de Gracia del convento franciscano, que en 1753 fue vaciada en estaño por un desconocido escultor portugués residente en Madrid Ilamado Ignacio Pereira. De su encargo y traslado a Colombia se ocupó fray Lope de San Antonio, procurador general de la provincia de Quito, durante el tiempo que estuvo en la corte negociando la concesión de una nueva misión para los franciscanos ${ }^{10}$.

El sacerdote Manuel Antonio Bueno también informó de la llegada a Popayán de otras esculturas de presunta procedencia española durante el siglo XVIII. Así, refiere que los padres camilos habían instalado en la iglesia una efigie de su fundador tallada en España, y en la iglesia de los dominicos menciona la existencia de un San José de vestir, comprado en Cádiz antes de 1744 por Francisco Arboleda, así como un Santo Domingo, sufragado por Asunción Tenorio y Arboleda. Al parecer, esta última escultura habría llegado a exponerse en la Real Academia de San Fernando antes de su partida para América. Siguiendo esta misma fuente, el convento de carmelitas descalzas también habría contado con al menos tres esculturas trabajadas en España: un San Juan de la Cruz, una Santa Teresa y una Virgen de la Soledad ${ }^{11}$. Los expolios sufridos por el patrimonio payanés impiden evaluar el grado de veracidad de estas noticias, pero en cualquier caso son testimonio de la estima alcanzada por la escultura española en una urbe que conoció un extraordinario desarrollo económico y demográfico durante el Setecientos, gracias a la explotación de las minas de oro.

En el mencionado templo del Carmen también se conserva un San Joaquín (Fig. 1), objeto de estudio de este trabajo, del que sorprendentemente el padre Bueno no señaló su procedencia española, aunque sí se percató de su calidad al calificarlo como obra "muy perfecta"12. Es probable que este olvido haya influido en la escasa fortuna crítica que ha merecido la pieza, que apenas es referida de pasada en los estudios como

\footnotetext{
7 José Antonio Vargas Jurado, La Patria Boba: tiempos coloniales, (Bogotá: Academia Colombiana de Historia, 1902), p. 47.

8 Sobre Laboria: Francisco J. Herrera García, "Pedro Laboria y la teatralidad elocuente en la escultura barroca bogotana", en El triunfo del barroco en la escultura andaluza e hispanoamericana, coords. Lázaro Gila Medina y F. J. Herrera García, (Granada: Universidad de Granada, 2018), pp. 507-536; Contreras Guerrero, Escultura en Colombia, pp. 259-324.

9 Sobre el papel de estos eclesiásticos como agentes intermediarios, en relación con la circulación de escultura napolitana: Luisa Elena Alcalá, "...Fatiga, y cuidados, y gastos, y regalos...": aspectos de la circulación de la escultura napolitana a ambos lados del Atlántico", Libros de la Corte, 5 Extra, (2017), pp. 163-184.

${ }_{10}$ Contreras Guerrero, Escultura en Colombia, p. 85.

11 Manuel Antonio Bueno y Quijano, "Compendio histórico y cronológico del Obispado de Popayán", en Historia de la Diócesis de Popayán. Compendio histórico y cronológico del Obispado de Popayán, vol. I, (Bogotá: Editorial ABC, 1945), pp. 22-25, 103, 119.

12 Bueno y Quijano, "Compendio histórico y cronológico", p. 119.
} 
Fig. 1. Pedro Duque Cornejo (aquí atribuido), San Joaquín, ca. 1720-1740. Popayán (Colombia), iglesia del Carmen, (c) Corporación Proyecto Patrimonio (Convenio 517 de 2014 con el Ministerio de Cultura de Colombia)

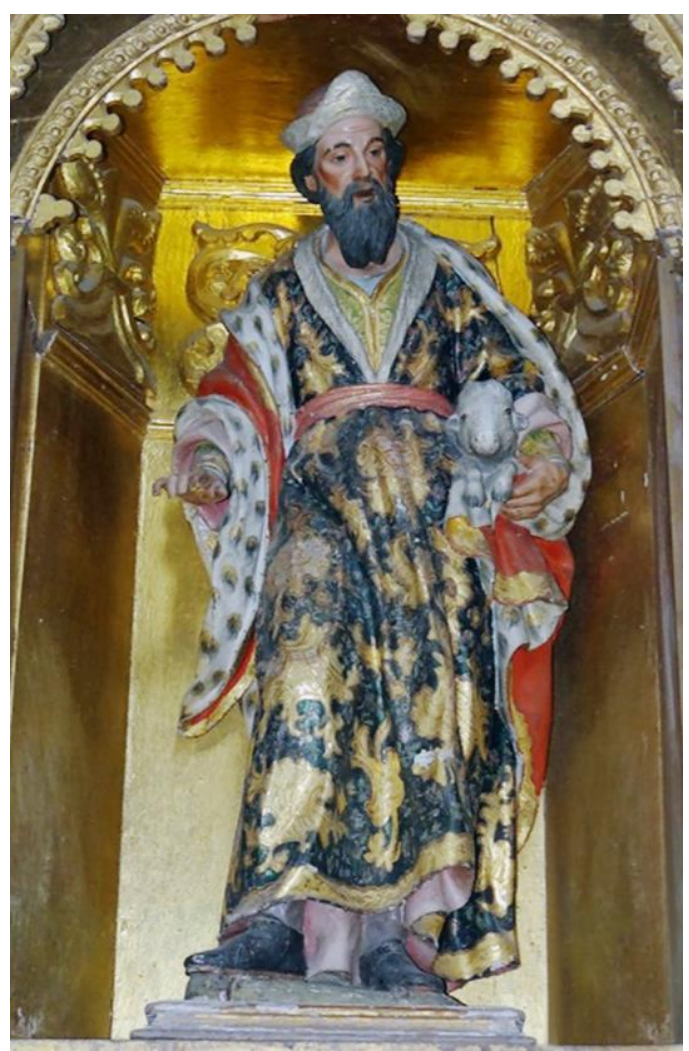

una anónima producción quiteña ${ }^{13}$. Esta catalogación se basa más en razonamientos de tipo geográfico o histórico que en argumentos de tipo estilístico o técnico. Ciertamente, Popayán estaba mejor comunicada con Quito que con la capital del virreinato y se encontraba bajo la jurisdicción de su Real Audiencia, lo que a la postre facilitó la relación entre ambas urbes y la consiguiente proyección de los obradores quiteños en los territorios meridionales de la actual Colombia. Sin embargo, la pieza que nos ocupa es una obra de indiscutible origen sevillano y perfectamente atribuible al escultor Pedro Duque Cornejo (1678-1757), el gran maestro de la escultura andaluza de su tiempo ${ }^{14}$.

Realizada en madera policromada y de tamaño ligeramente inferior al natural, la escultura representa al padre de la Virgen en pie, ataviado con una túnica talar, fajín, gorro orientalizante y un manto sobre los hombros. Para señalar su avanzada edad, Duque Cornejo concibió al santo algo encorvado, dejando caer su peso sobre un cayado -hoy perdido- que agarraba con su mano derecha. Las arrugas del rostro insisten en la misma idea, aunque el efecto se ve algo amortiguado por la paleta de color empleada por el policromador, que pintó la barba y el pelo con menos canas

${ }^{13}$ Contreras Guerrero, Escultura en Colombia, p. 182. También ha sido vinculada al taller santafereño de Pedro Laboria por Rosita Andrea Pantoja Barco, Afrodita Barroca. Fragmentos para el estudio de una sensibilidad de la cultura. Popayán, siglos XVII y XVIII, (Quito: Ediciones Abya-Yala, 2008), pp. 7 y 69.

${ }^{14}$ René Taylor, El entallador e imaginero sevillano Pedro Duque Cornejo, 1678-1757, (Madrid: Instituto de España, 1982); José Hernández Díaz, Pedro Duque Cornejo y Roldán (1678-1757), (Sevilla: Diputación Provincial, 1983); Manuel García Luque, Pedro Duque Cornejo: estudio de su vida y obra (1678-1757), tesis doctoral inédita, Universidad de Granada, (Granada, 2018). 
de lo habitual. En contrapartida, este anónimo maestro sí acertó al representar a San Joaquín como un personaje acaudalado -según la descripción que ofrece el Protoevangelio de Santiago- simulando piel de armiño en el forro del manto rojizo. Esta apariencia de hombre rico también se ve subrayada por los estofados, pues la trama decorativa elegida concede un gran protagonismo a los motivos cincelados en oro, que resaltan sobre el tono esmeralda de la túnica. Para completar su caracterización, el santo aparece sosteniendo un cordero bajo el brazo, en alusión a la ofrenda que hizo en el templo antes de retirarse al desierto con la intención de rogar a Dios por la ansiada descendencia.

Desde el punto de vista estilístico, la pieza reúne todos los caracteres de la obra madura de Duque Cornejo y su ejecución bien podría situarse entre 1720 y 1740 , durante la segunda etapa sevillana del artista. En este periodo él y sus oficiales realizaron otras seis esculturas de San Joaquín que han de tomarse como punto de referencia en el estudio de esta obra. Ninguna de ellas es igual a otra, lo que demuestra la fecunda inventiva y el método de trabajo del escultor, que siempre introducía variantes para ofrecer un producto original al cliente.

El tipo físico del San Joaquín de Popayán repite un prototipo habitual en las imágenes masculinas de Duque Cornejo, que aparece nítidamente definido por su nariz aguileña, el entrecejo triangular, los pómulos prominentes, el bigote ondulante y la espesa barba que se parte en dos sinuosas mitades. Estas facciones se repiten casi a la letra en el San Joaquín que forma un curioso grupo escultórico con Santa Ana y la Virgen Niña en la parroquia de Nuestra Señora del Rosario de Cádiz ${ }^{15}$. (Fig. 2) El blando modelado de la superficie, el tratamiento compacto y abocetado de los cabellos y la disposición ondulante de los plegados constituyen recursos técnicos y expresivos que también delatan la intervención del maestro sevillano.

A nivel compositivo, la imagen payanesa se puede poner en relación con al menos tres esculturas de San Joaquín que salieron del obrador de Duque Cornejo durante su segunda etapa en Sevilla. La más antigua sería la que figuró en el primer cuerpo retablos del retablo de la iglesia de San Teodomiro de Carmona (ca. 1722) -transferida en el siglo XX a la parroquial de Cantillana ${ }^{16}$-, seguida de la imagen realizada para el retablo de la iglesia de la Compañía de Córdoba $(1724)^{17}$. (Fig. 3) En ambos casos se trata de esculturas de madera policromada que ofrecen muy distintos niveles de calidad y acabado polícromo. Algo posterior en el tiempo resulta la escultura

\footnotetext{
${ }^{15}$ Manuel García Luque, "Duque Cornejo, el último barroco", Ars Magazine, 28, (2015), pp. 118-119.

${ }_{16}$ Manuel García Luque, "Dibujos de Duque Cornejo en el Álbum Jaffe (II): la colección del Hood Museum of Art", Philostrato. Revista de Historia y Arte, 4, (2018), p. 35, nota 12. (DOI: https://doi.org/10.25293/2018.18)

17 Ángel Aroca Lara, "La obra de Pedro Duque Cornejo en Córdoba: su labor escultórica en los retablos de la Magdalena y la Compañía", en Conferencias de los Cursos de Verano de la Universidad de Córdoba sobre "El barroco en Andalucía", dir. Manuel Peláez del Rosal, vol. III (Córdoba: Monte de Piedad y Caja de Ahorros de Córdoba, 1986), pp. 11-24.
} 
Fig. 2. Pedro Duque Cornejo, San Joaquín con la Virgen Niña en brazos (detalle), ca. 1730. Cádiz, iglesia de Nuestra Señora del Rosario de Cádiz, () Foto autor

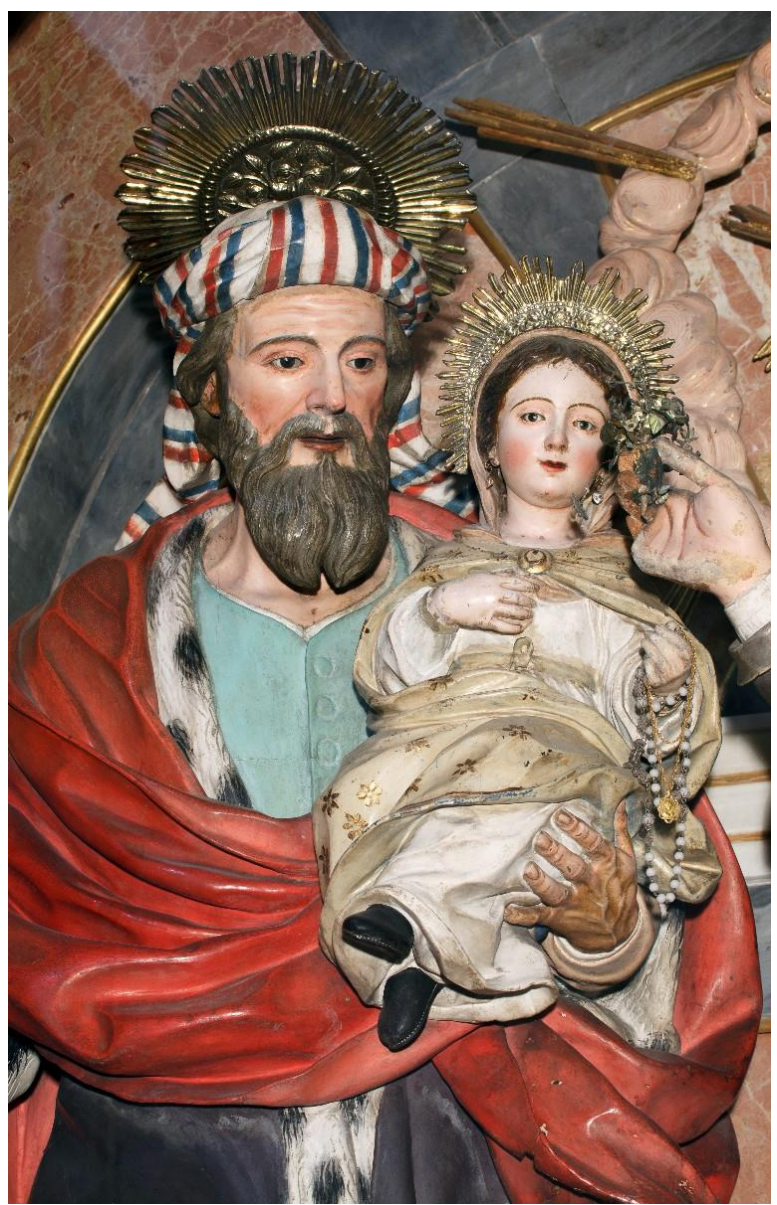

pétrea del retablo de la Virgen de la Antigua de la catedral de Sevilla (17341738) ${ }^{18}$. (Fig. 4) Pese a las ligeras variantes de pose y vestuario, las cuatro constituyen variaciones sobre un mismo modelo, en el que el santo aparece asiendo el cordero bajo el brazo y se apoya con la mano contraria en un bastón, lo que le vale al artista para generar un elegante contraposto. Del mismo modo, cabría apuntar un paralelo entre el ejemplo payanés y el estudio para una imagen de San Joaquín, realizado a tinta y aguada, que se conserva en el Hood Museum of Art (Hanover, EEUU). El sinuoso caracoleo de la túnica o el detalle del extremo picudo del manto, que se enrosca en uno de los brazos, demuestran la afinidad de recursos expresivos ${ }^{19}$. (Fig. 5)

Aclarada la cuestión de su autoría, queda por conocer cuándo y en qué circunstancias se produjo la llegada de la escultura a Colombia. A estas incógnitas podrían dar respuesta los documentos del archivo conventual, pero lamentablemente este se perdió después de que las monjas fueran exclaustradas en 1863 y tuvieran que fundar un nuevo convento en Ibarra

${ }^{18}$ Heliodoro Sancho Corbacho, Arquitectura sevillana del siglo XVIII, col. Documentos para la Historia del Arte en Andalucía, vol. VII, (Sevilla: Laboratorio de Arte, 1934), pp. 10-12; Taylor, El entallador e imaginero, p. 51.

19 García Luque, "Dibujos de Duque Cornejo", pp. 34-35. 


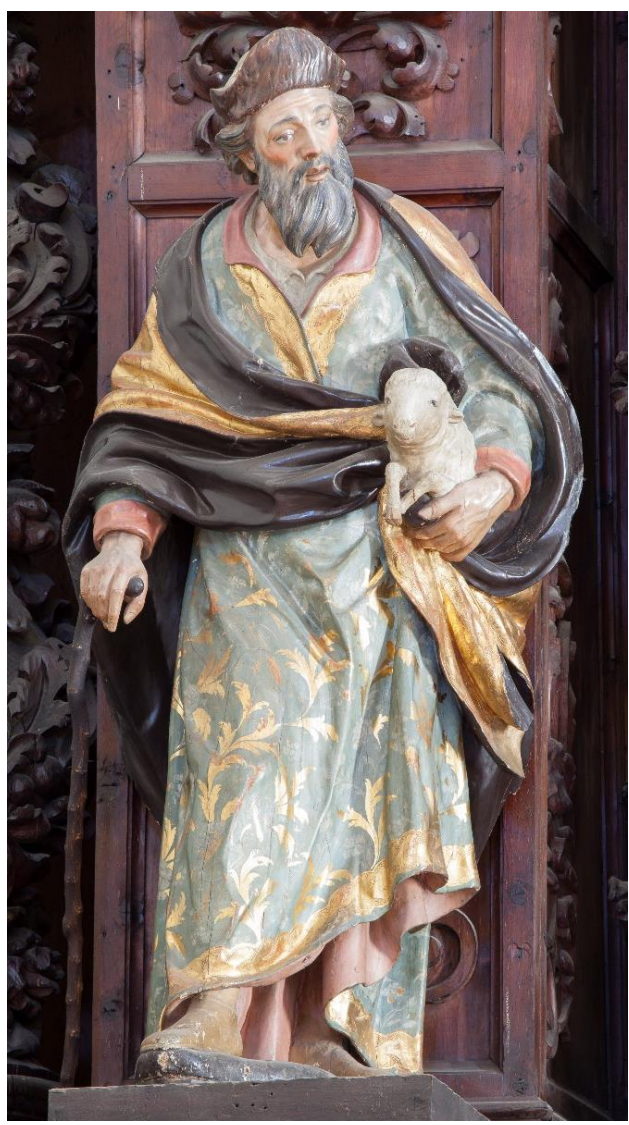

Fig. 3. Pedro Duque Cornejo, San Joaquín, 1724. Córdoba, iglesia de San Salvador y Santo Domingo de Silos, (C) Foto autor

(Ecuador), por lo que por el momento solo cabe conjeturar algunas hipótesis ${ }^{20}$.

El convento de carmelitas descalzas de Popayán fue fundado por iniciativa de Baltasar Carlos Pérez de Vivero (†1728) y Dionisia Pérez Manrique y Camberos (†1744), marqueses de San Miguel de la Vega. Él era un indiano de origen granadino que hizo fortuna en América, lo que le permitió alcanzar el título nobiliario en 1706 y desempeñar el cargo de gobernador y capitán general de Popayán ${ }^{21}$. Ella era una dama criolla, hija del I marqués de Santiago, que había estado casada en primeras nupcias con Diego José de Velasco (1656-1708) 22 . Tras contraer matrimonio y no lograr descendencia, ambos decidieron invertir parte de su pingüe fortuna en la erección de un convento femenino, ofreciendo para este propósito las casas de su morada y fincas por valor de 70.000 patacones con el objeto de "edificar yglesia, imponer renta al capellan, hacer ornamento y todo lo de-

20 Tras la exclaustración permanecieron algunos meses en Popayán en una casa particular, hasta que marcharon a Quito el 28 de abril de 1864. Allí estuvieron interinamente hasta que viajaron a Ibarra para hacer la nueva fundación. Bueno y Quijano, Historia de la diócesis, pp. 121-123.

${ }^{21}$ La compra del título llevaba aparejada el cargo de gobernador de Popayán. Asimismo, en 1709 compró el cargo de gobernador y presidente de la Audiencia de Santa Fe de Bogotá. María del Mar Felices de la Fuente, La nueva nobleza titulada de España y América en el siglo XVIII (1701-1746): entre el mérito y la venalidad, (Almería: Universidad de Almería, 2012), p. 268.

22 Gregorio César de Larrea, "Más datos sobre los Larrea", Boletín de la Academia Nacional de Historia, 199, (2018), p. 454. 
Fig. 4. Pedro Duque Cornejo, San Joaquín, 17341738. Sevilla, catedral, (C) Foto autor

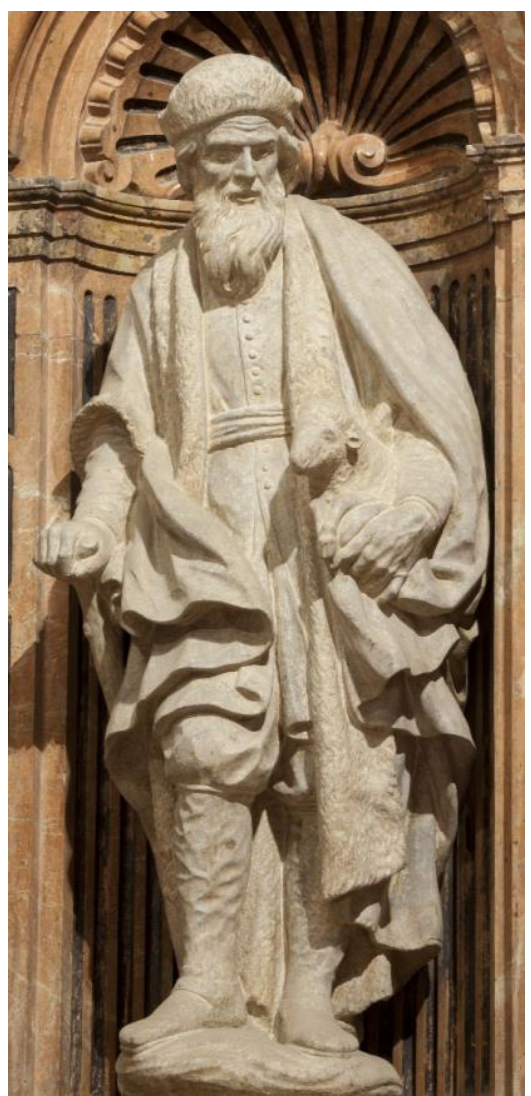

mas necesario"23. Los trámites para la fundación se iniciaron formalmente en 1720, tras recabar el apoyo del gobernador de la ciudad, de los cabildos municipal y catedralicio, y del obispo Juan Gómez de Nava (ca. 1666-1729). La oposición del convento de agustinas de la Encarnación y de los frailes dominicos parece que no fue un obstáculo para que el fiscal nombrado por el Consejo de Indias emitiese un informe favorable. No obstante, aún tuvieron que sortearse algunas trabas impuestas por la Corona, reticente a nuevas fundaciones. Tras contar con otro informe positivo de la Real Audiencia de Quito y recabar nuevos apoyos en las ciudades vecinas de Cali y Buga, los marqueses lograron la ansiada licencia real el 3 de junio de 1724. Todavía tuvieron que pasar cinco años para que, una vez saneado el caudal eliminando los gravámenes que pesaban sobre los bienes aportados, se otorgara la escritura fundacional el 14 de marzo de 1729, muerto ya el marqués ${ }^{24}$.

Las cinco monjas procedentes del convento del Carmen de Bogotá hicieron su entrada solemne en Popayán el 14 de octubre de aquel año. Inicialmente se instalaron en las referidas casas de Dionisia Manrique, que

23 Archivo General de Indias (en adelante, AGI), Quito, Leg. 143, N. 58h., Sobre instancia de los marqueses de San Miguel de la Vega en cuanto a la fundación de un convento de carmelitas en Popayán, 22 de agosto, 1722.

${ }^{24}$ Sobre la fundación: Clemente de Tulcán, Crónica de la fundación del Monasterio de las RR. MM. Carmelitas de Ibarra, (Ibarra: Talleres Tipográficos Municipales, 1946); Hernán Arboleda Valencia, "Las Monjas Carmelitas y su Nuevo Monasterio", Popayán (298), (1978), pp. 123-128. 
comprendían una de las manzanas linderas con la plaza mayor, aunque enseguida se compraron dos solares y una casa en la calle de Belén para levantar el convento y la iglesia en un área menos bulliciosa. Las obras fueron dirigidas por el arquitecto santafereño Gregorio Causí, llamado a este efecto por la marquesa ${ }^{25}$. Santiago Sebastián sitúa esta venida a raíz del devastador terremoto que asoló la ciudad en 1736, aunque los datos son algo confusos ${ }^{26}$. Así, en el codicilo de la marquesa, otorgado en noviembre del año siguiente, ésta mandaba abonar al vicario general de la diócesis las demasías que había tenido la construcción del "tabernáculo [-léase retablo-] del Carmen", puesto que él había administrado un legado de 2.000 patacones que había dejado el mercader Miguel de Peñalver y se emplearon para este fin. Si, como parece, el documento se refiere al retablo mayor, para entonces la fábrica de la iglesia ya debía estar completamente concluida ${ }^{27}$.

Mientras que el convento fue dedicado a San José -devoción teresiana por antonomasia-, la iglesia se consagró en honor de San Joaquín ${ }^{28}$. Ello constituye un rasgo típico de la religiosidad dieciochesca, pues el creciente fervor mariano favoreció que el culto tributado a los padres de la Virgen conociera un extraordinario auge en esta centuria ${ }^{29}$. Pese a que su imagen no se entronizó en el retablo mayor, el santo tuvo un importante peso en el universo devocional de la comunidad, pues su fiesta se celebraba con gran pompa el domingo siguiente a la fiesta de la Asunción y su altar era el único que, junto al mayor, gozaba de privilegio perpetuo por concesión de Pío $\mathrm{VII}^{30}$. Considerando estas circunstancias, no tiene nada de particular que se quisiera contar con una escultura realizada en un taller sevillano, pues, pese al riesgo y el sobrecoste que entrañaba su viaje transatlántico, la adquisición de una obra de empeño prestigiaba a la naciente comunidad y podía constituir un reclamo para los fieles en un marco urbano donde las carmelitas, por su tardía fundación, jugaban en clara desventaja frente a otras comunidades ya enraizadas en el entramado social de la ciudad, como era el caso de los dominicos, los franciscanos o las agustinas. Además, es posible que la compra del San Joaquín no constituyera un caso aislado, pues

\footnotetext{
${ }^{25}$ Arcesio Aragón, Fastos Payaneses, 1536-1936, vol. II, (Bogotá: Imp. Nacional, 1940), p. 35.

${ }^{26}$ De hecho, Gregorio Causí también intervino en la reconstrucción de las iglesias de Santo Domingo y San Agustín. Santiago Sebastián, Itinerarios artísticos de la Nueva Granada, (Popayán: Academia de Historia del Valle del Cauca, 1965), p. 193; Santiago Sebastián, Arquitectura Colonial en Popayán y Valle del Cauca, (Cali: Biblioteca de la Universidad del Valle, 1965), p. 42.

27 Archivo Histórico del Centro de Investigaciones Históricas José María Arboleda Llorente, Universidad del Cauca (Popayán) (en adelante, AHUC), Notaría Única de Popayán, tomo 30, escritura 113, fol. 201r, Codicilo de Dionisia Pérez Manrique, marquesa de San Miguel de la Vega, 8 de noviembre, 1737:

"Asimesmo debe al señor provisor y vicario general doctor don Francisco Xavier Thorixemo por haver corrido con el costo y gasto del tabernaculo para el Carmen lo que pareciere haver pasado de dos mil pattacones de manda que hiso don Miguel de Peñalvert al dicho Carmen, los que se embebieron en el referido tavernaculo y lo más que fuere es lo que se le debe a dicho señor manda se le paguen".

El bienhechor, un mercader español natural de Alcalá la Real, había dispuesto exactamente lo siguiente: "Ytem mando que al convento de monxas carmelitas de esta ciudad de Popayan se les den dos mill pattacones de limosna para que los empleen en ornamentos". AHUC, Notaría Unica de Popayán, tomo 28, escritura 24, fol. 39r., Testamento de Miguel de Peñalver, 14 de febrero, 1734.

28 Sebastián, Itinerarios artísticos, p. 193.

29 Sobre este auge devocional ya reparó Herrera García, "Pedro Laboria", p. 529.

30 Bueno y Quijano, Historia de la diócesis, p. 120.
} 


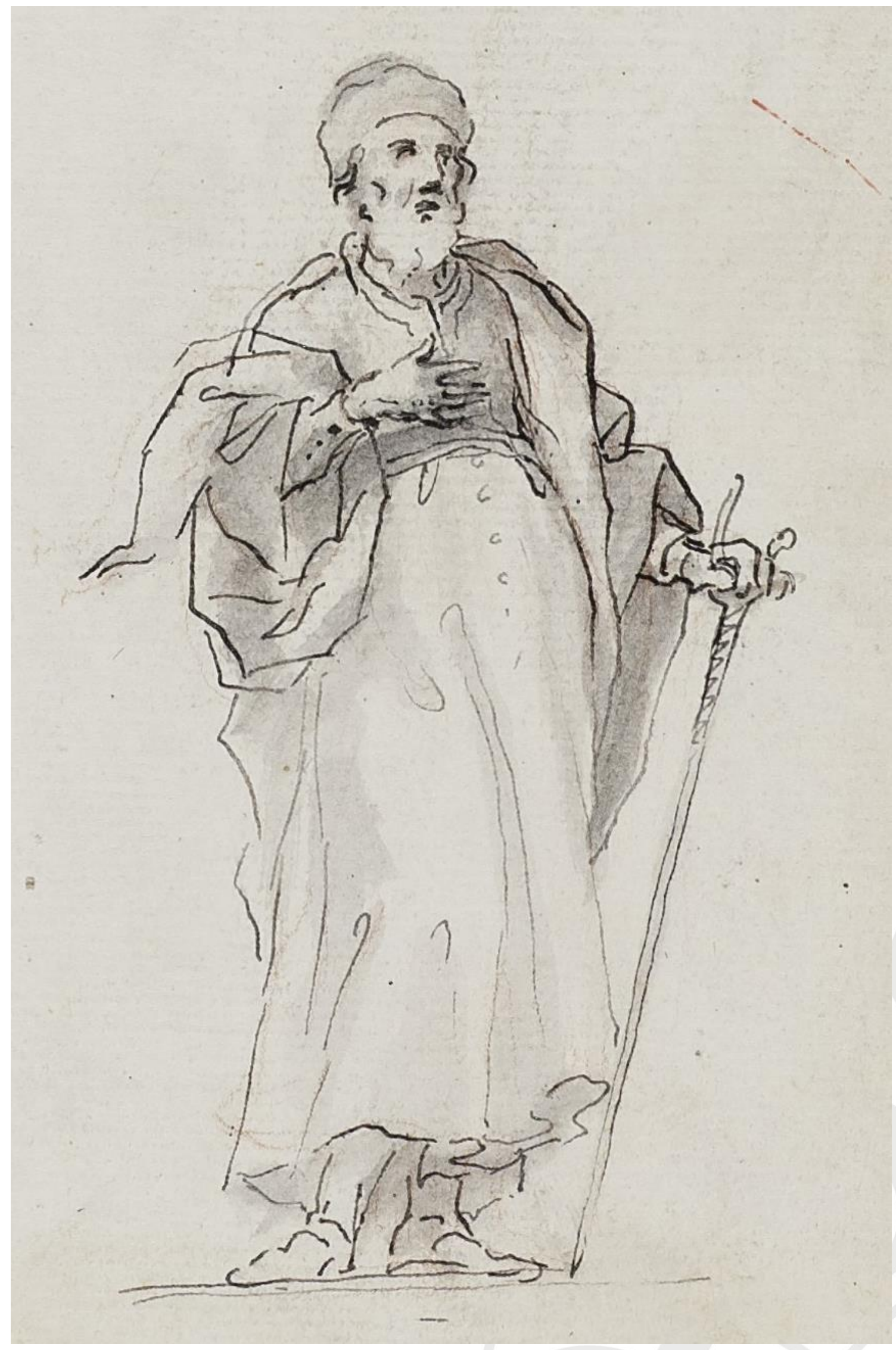

Fig. 5. Pedro Duque Cornejo, San Joaquín, ca. 1710-1740. Hanover, Darmouth College, ( The Hood Museum of Art 
como más arriba se apuntó, en la iglesia también existieron otras esculturas a las que Bueno atribuye una procedencia española ${ }^{31}$.

Pese a que los intereses que pudieron motivar su encargo están más o menos claros, está por ver quién promovió y financió la operación. Por un lado, sabemos que la marquesa sobrevivió hasta 1744, lo que permite barajarla como potencial mecenas y promotora, pues tanto ella como su marido se habían comprometido a "ornamentar la yglesia competentemente" y a dedicar "las alajas que tienen en su casa para el seruicio de la sacristia e yglesia"32. Entre estas prendas donadas para el culto divino se encontraba una rica custodia de plata sobredorada, engastada de diamantes, esmeraldas, perlas y piedras coloradas ${ }^{33}$.

Además del generoso capital fundacional, la comunidad contaba con sustanciosos ingresos provenientes de las dotes de las primeras religiosas que fueron profesando en el convento, en su mayor parte pertenecientes a la más distinguida nobleza de Popayán. El caso más significativo fue el de María Manuela de la Encarnación Carvajal y Lasprilla, que ingresó en 1730 con una fortuna valorada en 92.000 pesos, empleados para costear, entre otras dádivas, un trono chapado de plata para la imagen de Santa Teresa ${ }^{34}$. En ello debió de influir el nombramiento de la religiosa como síndica de la santa, cargo que llevaba aparejado el cuidado de la imagen, de su altar y de su ajuar, además de la responsabilidad de organizar su fiesta. En el caso del San Joaquín desconocemos qué religiosas fueron sus síndicas en el periodo que nos interesa, aunque consta que la escultura llegó a tener una diadema de plata y un cordón "de muchos hilos de perlas muy finas que le daban la vuelta al cuerpo", que tal vez fueron adquiridos por análogo procedimiento ${ }^{35}$.

Sin saber si la escultura fue sufragada por la fundadora, la comunidad o algún particular, tampoco resulta fácil identificar a los diferentes agentes e intermediarios que pudieron estar involucrados en su encargo y transporte. No obstante, el hallazgo de un documento notarial podría arrojar algo de luz en este asunto. Se trata de un poder, fechado el 15 de marzo de 1730 y dado por la priora de las carmelitas al padre jesuita Ignacio Meaurio (16701751), procurador de la provincia del Nuevo Reino de Granada en las cortes de Madrid y Roma, así como "a su compañero qualquiera que fuesse de dicha compañia", para que representasen a las religiosas en todos sus negocios, "en expesial para lo que tiene encargado por carthas priuadas" 36.

\footnotetext{
31 Bueno y Quijano, Historia de la diócesis, p. 119.

32 AGI, Quito, Leg. 143, N. 58b, Memorial de los marqueses de San Miguel de la Vega al rey, pidiendo licencia para fundar un convento de carmelitas en Popayán, s.d.

33 Bueno y Quijano, Historia de la diócesis, p. 117.

34 Bueno y Quijano, Historia de la diócesis, pp. 117-118; Aragón, Fastos Payaneses, p. 50.

35 Estas alhajas serían llevadas por las monjas en su exilio a Ecuador, donde las venderían para sufragar la construcción del nuevo convento. Bueno y Quijano, Historia de la diócesis, p. 118.

${ }^{36}$ AHUC, Notaría única de Popayán, tomo 27, escritura 34, fol. 63r-v, Poder que da Bárbara Jesús María Santísima de la Trinidad, priora del convento de carmelitas descalzas, al padre Ignacio Meaurio, procurador general de la Compañía de Jesús del colegio de Santa Fe de Bogotá, 15 de marzo, 1730.
} 
En aquel tiempo el procurador se encontraba en Europa reclutando misioneros, con los que embarcó de regreso a América en 1735 37 . Lo habitual era que estos expedicionarios se alojaran en el Hospicio de Indias de Sevilla hasta que zarpara la embarcación ${ }^{38}$, lo que pudo brindar al padre Meaurio la oportunidad de encargar el San Joaquín al taller de Duque Cornejo. Nada extraño, por otra parte, teniendo en cuenta la magnífica relación que el escultor mantenía con los jesuitas hispalenses, para los que se encontraba ejecutando en aquellos años el fastuoso conjunto de retablos y esculturas de la iglesia del noviciado de San Luis, sin olvidar otros muchos trabajos realizados para diferentes colegios de la provincia Bética ${ }^{39}$. Entre ellos cabría recordar alguno de proyección atlántica, como el San Francisco de Borja (1732) del colegio de Las Palmas de Gran Canaria, que Duque Cornejo esculpió por mediación del padre Juan de Arana ${ }^{40}$.

La hipótesis, aunque necesitada de refrendo documental, resulta plenamente viable, puesto que, según ha demostrado Luisa Elena Alcalá, los procuradores jesuitas solían aprovechar su estancia europea para gestionar numerosos negocios privados. Estas gestiones resultaban de lo más variadas, e incluían desde el negociado de asuntos religiosos -como la obtención de indulgencias, dispensas y jubileos-, hasta el envío de dinero, cartas y regalos a particulares, o la compra por encargo de libros, estampas y toda suerte de manufacturas artísticas, entre las que por supuesto se incluían esculturas y pinturas. De este modo, los procuradores prestaban un importante servicio a la sociedad virreinal como agentes comerciales, lo que en la práctica les permitía fidelizar su red clientelar y afianzar el poder de la Compañía de Jesús en América ${ }^{41}$.

Si el San Joaquín de Duque Cornejo llegó a Popayán en 1735 de mano de los jesuitas es un extremo que por el momento no podemos confirmar, pero no cabe duda de que ya se encontraba en el convento en 1758. En este año, el presbítero Francisco Javier de Oviedo indicaba en su testamento que aún le debía al deán de la catedral, José Prieto de Tobar, "cuatrocientos libros de oro que me dio prestados para dorar el tabernáculo de mi Padre San Joaquín en el convento del Carmen"42. El retablo, de un solo cuerpo y ático, responde a la modalidad salomónica y se halla cubierto por una tupida red vegetal (Fig. 6). Pese a que se ubica en un lugar secundario del templo, en uno de los testeros de la nave, todo apunta a que este fue el retablo originario de la imagen, pues en su coronación aparece una imagen

\footnotetext{
37 José del Rey Fajardo, Los jesuitas en Venezuela, tomo II, Los hombres, (Caracas-Bogotá: Universidad Católica Andrés Bello-Pontifica Universidad Javeriana, 2006), p. 320.

${ }^{38}$ Así continuó ocurriendo incluso en el siglo XVIII. Agustín Galán García, El "Oficio de Indias" de Sevilla y la organización económica y misional de la Compañía de Jesús (1566-1767), (Sevilla: Fundación Fondo de Cultura de Sevilla, 1995), p. 173.

39 Sobre sus trabajos en San Luis, véase Juan Luis Ravé Prieto, San Luis de los Franceses, (Sevilla: Diputación Provincial, 2018).

40 Carmen Fraga González, "Santa Bárbara de Icod y el arte de Duque Cornejo", Boletín de Bellas Artes, 10, (1982), pp. 205-206.

41 Luisa Elena Alcalá, "'De compras por Europa': procuradores jesuitas y cultura material en Nueva España, Goya, 318, (2007), pp. 143-144; Alcalá, "...Fatiga, y cuidados", pp. 163-184.

42 Adrián Contreras Guerrero, Historia del retablo neogranadino (1550-1800), (Córdoba: Ucopress, 2020), p. 242.
} 


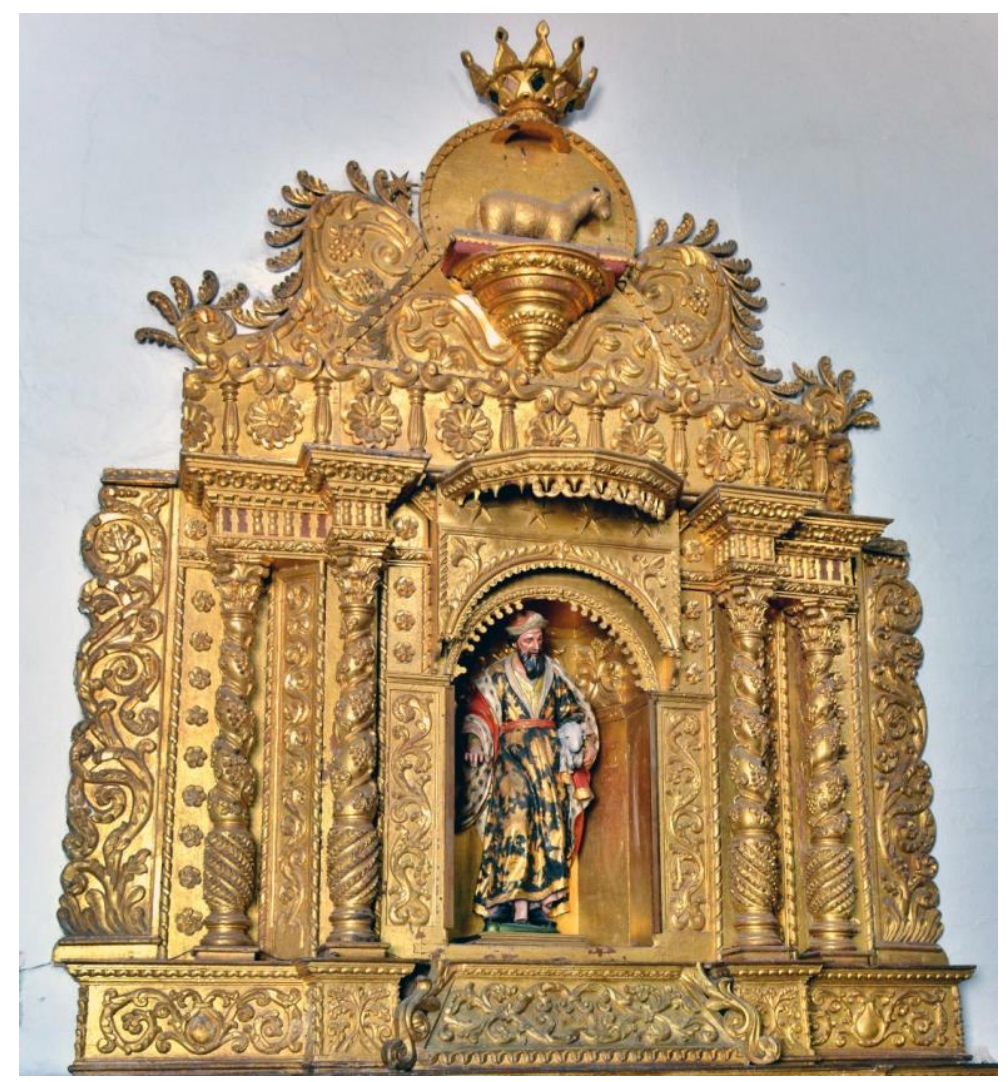

Fig. 6. Anónimo, Retablo de San Joaquín, ca. 1750-1758. Popayán (Colombia), @ iglesia del Carmen

de bulto del cordero. En la repisa que lo sostiene se grabó la inscripción latina Lucerna eius est agnus ("Su lámpara es el Cordero"), extraída del libro del Apocalipsis $(21,23)$, con la que se juega con el doble sentido del atributo del santo, que se identifica como símbolo de Cristo redentor.

Otra prueba irrefutable de que la imagen se encontraba en Popayán desde mediados del siglo XVIII la tenemos en la existencia en la ciudad de otras tres esculturas en madera policromada que copian con bastante fidelidad su modelo. Este parentesco ya fue advertido por Santiago Sebastián, aunque juzgó que la cabeza de serie sería el ejemplar de la catedral, que relacionó - de forma poco consistente- con el taller del escultor quiteño Manuel Chili "Caspicara" (ca. 1723-1796), y consideró réplicas las imágenes de las iglesias del Carmen, Santo Domingo y San Francisco ${ }^{43}$.

De nuevo, la falta de noticias impide reconstruir la secuencia temporal de los acontecimientos y no podemos determinar cuál de las copias se realizó en primer lugar. Desde luego, la de mejor calidad es la de la iglesia de San Francisco, que tras el devastador terremoto de 1983 pasó al Museo Arquidiocesano ${ }^{44}$. (Fig. 7) Su fidelidad al original es tal que en otro contexto

${ }^{43}$ Sebastián, Itinerarios artísticos, pp. 176, 180, 188 y 193.

${ }^{44}$ Es posible que en este funesto episodio perdiera la mano derecha. 


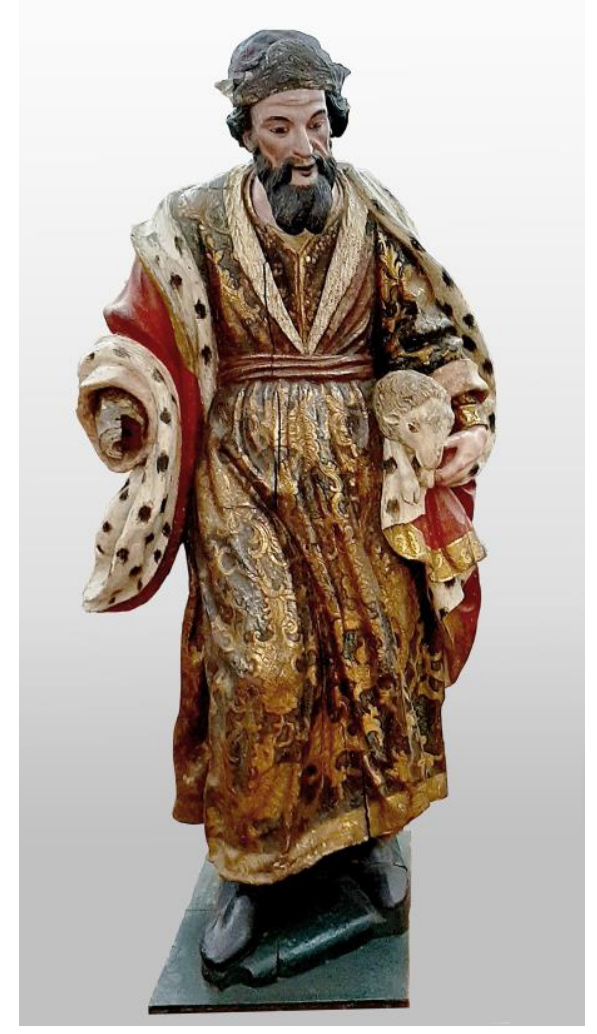

Fig. 7. Anónimo americano copiando a Duque Cornejo, San Joaquín, ca. 1750-1800, Popayán (Colombia), (C) Museo Arquidiocesano

podría haber pasado por una réplica del taller de Duque. Sin embargo, esta posibilidad debe ser descartada, pues no era habitual que el maestro repitiera una composición con tal grado de literalidad $y$, aunque así se lo hubiera requerido el cliente, habría resultado muy difícil hacerlo con una obra que ya se encontraba al otro lado del Atlántico, basándose únicamente en el modelo de barro o en algún dibujo guardado a modo de ricordo. Otro aspecto a considerar es que la imagen de San Francisco copia de forma evidente el cromatismo de la original y recrea, de forma algo más libre, el diseño de sus estofados, con las peculiares redes de rombos ceñidas por motivos rizados. Esta circunstancia refuerza la hipótesis de que nos encontramos ante una buena copia de factura local, dado que las esculturas de Duque Cornejo solían salir del taller en blanco -esto es, en madera en su color-, y el copista fue alguien que tuvo a la vista una escultura completamente acabada de talla y policromía.

Por desgracia, es muy poco lo que conocemos de la actividad de los talleres payaneses ${ }^{45}$, aunque por algunas noticias dispersas sabemos de la existencia de un desconocido Francisco de Prado, fallecido en 1777, que se

45 Sobre esta cuestión Francisco Javier Herrera García prepara un trabajo titulado "Noticias y observaciones sobre la demanda y actividad escultórica en Popayán en la primera mitad y años centrales del siglo XVIII", donde según nos informa el autor también se abordará el estudio de esta serie de esculturas de San Joaquín. 


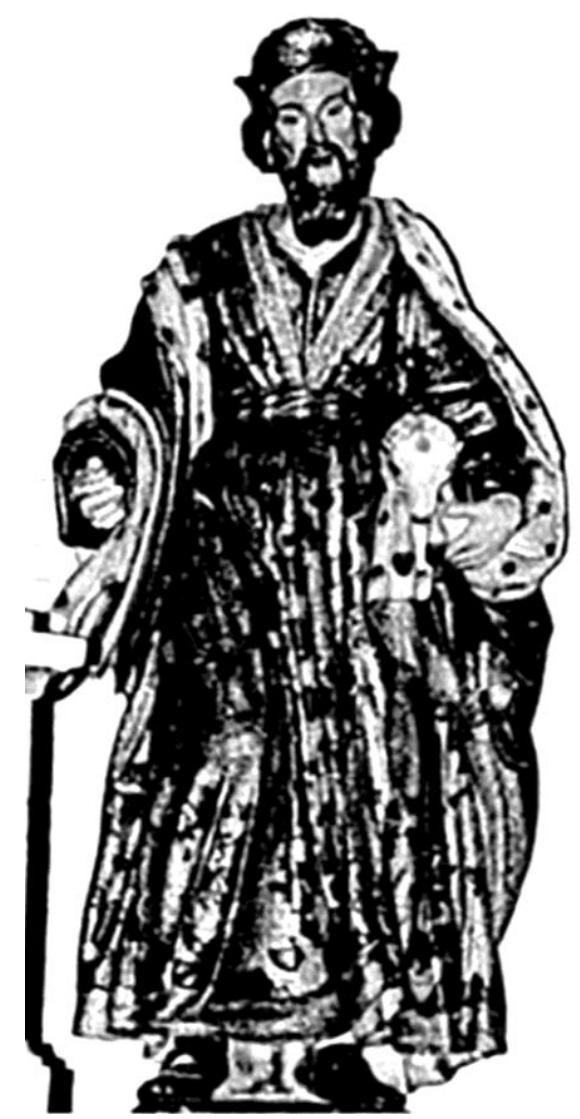

Fig. 8. Anónimo americano copiando a Duque Cornejo, San Joaquín, ca. 1750-1800. Popayán (Colombia), catedral de Nuestra Señora de la Asunción, Foto: Alfredo Valderruten en Pantoja Barco (2008, p. 68)

declaraba "profesor tanto de talla como de pincel"46. Más interesante resulta el caso del polifacético Roque Navarrete, un soldado que en 1788 se identificaba como "escultor y tallador en madera, piedra y marfil"47. En el decenio de 1740 este escultor había trabajado para los franciscanos realizando las esculturas pétreas de la portada de su iglesia, lo que deja abierta la posibilidad de que los frailes también le encomendaran la ejecución de la copia en madera del San Joaquín del Carmen. Por otra parte, tampoco cabe descartar que su autor fuera un escultor quiteño como sostuvo Santiago Sebastián ${ }^{48}$-, que en todo caso tuvo que desplazarse a Popayán para conocer el original.

Idéntica problemática concurre con los ejemplares de la catedral y Santo Domingo, que han sido indistintamente catalogados como obras quiteñas o santafereñas, al haberse relacionado - con poco fundamento estilísticocon la producción de escultores como Caspicara, Bernardo de Legarda (ca. 1700-1773) o Pedro Laboria ${ }^{49}$. La escultura del templo metropolitano carece

\footnotetext{
${ }^{46}$ Contreras Guerrero, Escultura en Colombia, pp. 181-182.

${ }^{47}$ Luis Alberto Acuña, Historia Extensa de Colombia: las artes en Colombia, t. III, La Escultura, (Bogotá: Lerner, 1967), p. 185. Adrián Contreras Guerrero, In ligno facta. Artes escultóricas de los siglos XVII y XVIII en Colombia, tesis doctoral, Universidad de Granada, (Granada: 2018), pp. 17 y 485. (En web: https://digibug.ugr.es/handle/10481/54076, consultada el 1 de octubre de 2021).

48 Sebastián, Itinerarios artísticos, p. 188.

49 Pantoja Barco, Afrodita Barroca, p. 69; Contreras Guerrero, Escultura en Colombia, p. 182; Raúl Ortiz Toro, Los templos históricos de Popayán, (Cali: Arquidiócesis de Popayán, 2016), pp. 21 y 58.
} 
Fig. 9. Anónimo americano copiando a Duque Cornejo, San Joaquín, ca. 1750-1800. Popayán (Colombia), ( ) iglesia de Santo Domingo

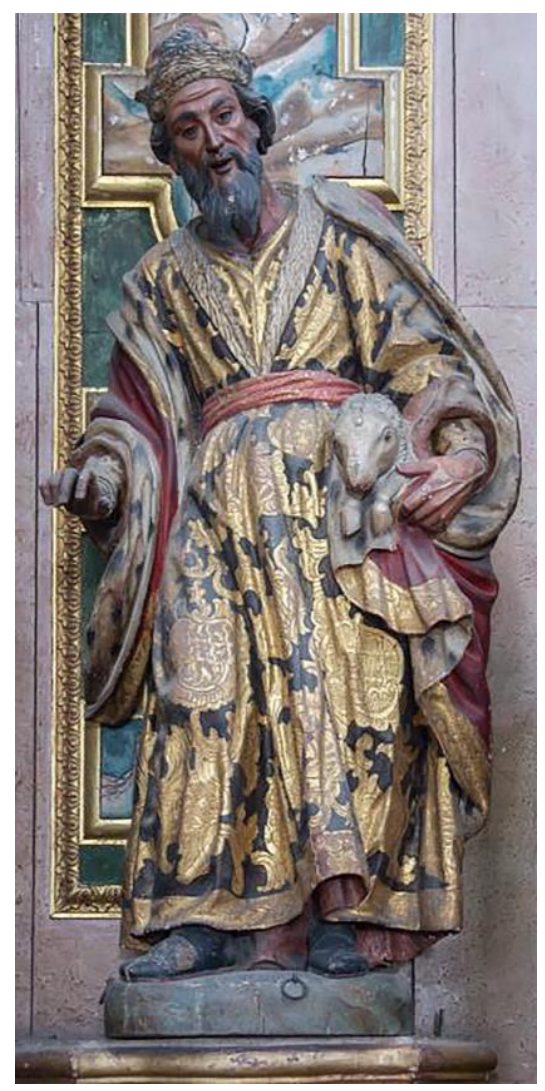

de la gracia y la naturalidad del original, aunque resulta una obra notable que reproduce con relativa precisión el modelo de Duque. Se dispone en la capilla de la Inmaculada, donde hace pareja con una escultura de Santa Ana, flanqueando una imagen de la Inmaculada apocalíptica que se basa en el popular modelo de la Virgen alada divulgado por Legarda. (Fig. 8)

La escultura de la iglesia de Santo Domingo constituye la copia más libre de la serie y delata ser obra de un artífice que, aun trabajando sobre un modelo ajeno, posee cierta personalidad (Fig. 9). También esta aparece emparejada con una escultura de Santa Ana -muy cercana a la imagen de la catedral- y ambas se exhiben en los intercolumnios del retablo mayor, una obra factura neoclásica ejecutada por el entallador Camilo Guevara sobre un diseño del presbítero y arquitecto Marcelino Arroyo (1764-1833) ${ }^{50}$.

Como conclusión, la existencia de esta serie de copias no hace sino testimoniar el impacto logrado por un modelo de Duque Cornejo en un ámbito tan alejado de Sevilla como la remota Popayán. Allí, su peculiar lenguaje creativo pudo ser admirado como un reflejo de la escultura barroca más a la moda que se hacía en Europa. Sin embargo, sería erróneo juzgar este episodio desde un punto de vista exclusivamente artístico o estético, puesto que la reiteración del modelo puede esconder otro tipo de motivaciones de tipo religioso o incluso económico, si es que en algún momento los franciscanos, los dominicos o el clero capitular quisieron

${ }^{50}$ Aragón, Fastos payaneses, p. 35. 
capitalizar parte del éxito devocional logrado por el San Joaquín de las carmelitas.

Por otra parte, el hallazgo de una escultura de Duque Cornejo en este rincón del antiguo virreinato de Nueva Granada otorga a su taller una proyección americana desconocida hasta la fecha, y abre la puerta a que en el futuro puedan ser localizadas en el continente nuevas obras del artista o de otros escultores sevillanos contemporáneos, lo que sin duda serviría para aclarar si nos encontramos ante un episodio puntual de patrocinio artístico o, por el contrario, existió algún tipo de comercio de escultura entre Sevilla y América durante el siglo XVIII, cuya historia aún está por escribir. 
Fuentes documentales:

Archivo General de Indias (AGI)

- Quito, leg.143, N. 58b, Memorial de los marqueses de San Miguel de la Vega al rey, pidiendo licencia para fundar un convento de carmelitas en Popayán, s.d.

- Quito, leg. 143, 22, N. 58h, Sobre instancia de los marqueses de San Miguel de la Vega en cuanto a la fundación de un convento de carmelitas en Popayán, 22 de agosto, 1722.

Archivo Histórico del Centro de Investigaciones Históricas José María Arboleda Llorente, Universidad del Cauca (Popayán) (AHUC)

- Notaría única de Popayán, tomo 27, escritura 34, fol. 63r-v, Poder que da Bárbara Jesús María Santísima de la Trinidad, priora del convento de carmelitas descalzas, al padre Ignacio Meaurio, procurador general de la Compañía de Jesús del colegio de Santa Fe de Bogotá, 15 de marzo, 1730.

- Notaría Única de Popayán, tomo 28, escritura 24, fol. 36v-40r, Testamento de Miguel de Peñalver, 14 de febrero, 1734.

- Notaría Única de Popayán, tomo 30, escritura 113, fol. 200v-202v, Codicilo de Dionisia Pérez Manrique, marquesa de San Miguel de la Vega, 8 de noviembre, 1737. 
Bibliografía:

Acuña 1967: Luis Alberto Acuña, Historia Extensa de Colombia: las artes en Colombia, t. III, La Escultura, (Bogotá: Lerner, 1967).

Alcalá 2007: Luisa Elena Alcalá, "De compras por Europa": procuradores jesuitas y cultura material en Nueva España, Goya, 318, (2007), pp. 141158.

Alcalá 2017: Luisa Elena Alcalá, "...Fatiga, y cuidados, y gastos, y regalos...": aspectos de la circulación de la escultura napolitana a ambos lados del Atlántico", Libros de la Corte, 5 Extra, (2017), pp. 163-184.

Angulo Iñiguez 1935: Diego Angulo Íñiguez, "Dos Menas en Méjico. Esculturas sevillanas en América", Archivo Español de Arte y Arqueología, 31, (1935), pp. 131-152.

Aponte Pareja 2014: Jesús Andrés Aponte Pareja, Escultura en el Nuevo Reino de Granada. Siglos XVI-XVII, (Bogotá: J. Aponte, 2015).

Aragón 1941: Arcesio Aragón, Fastos Payaneses, 1536-1936, vol. II, (Bogotá: Imp. Nacional, 1940).

Arboleda Valencia 1978: Hernán Arboleda Valencia, "Las Monjas Carmelitas y su Nuevo Monasterio", Popayán (298), (1978), pp. 123-129.

Aroca Lara 1979: Ángel Aroca Lara, "La obra de Pedro Duque Cornejo en Córdoba: su labor escultórica en los retablos de la Magdalena y la Compañía", en Conferencias de los Cursos de Verano de la Universidad de Córdoba sobre "El barroco en Andalucía", dir. Manuel Peláez del Rosal, vol. III, (Córdoba: Monte de Piedad y Caja de Ahorros de Córdoba, 1986), pp. 11-24.

Bernales Ballesteros 1981: Jorge Bernales Ballesteros, "Escultura montañesina en América", Anuario de Estudios Americanos, 38, (1981), pp. 499-566.

Bueno y Quijano 1945: Manuel Antonio Bueno y Quijano, "Compendio histórico y cronológico del Obispado de Popayán", en Historia de la Diócesis de Popayán. Compendio histórico y cronológico del Obispado de Popayán, vol. I, (Bogotá: Editorial ABC, 1945).

Contreras Guerrero 2018: Adrián Contreras Guerrero, In ligno facta. Artes escultóricas de los siglos XVII y XVIII en Colombia, tesis doctoral. Universidad de Granada. (Granada: 2018). (En web: https://digibug.ugr.es/handle/10481/54076, consultada el 1 de octubre de 2021). 
Contreras Guerrero 2019: Adrián Contreras Guerrero, Escultura en Colombia: focos productores y circulación de obras (siglos XVI-XVIII), (Granada: Universidad de Granada, 2019).

Contreras Guerrero 2020: Adrián Contreras Guerrero, Historia del retablo neogranadino (1550-1800), (Córdoba: Ucopress, 2020).

Estella Marcos 1990: Margarita Estella Marcos, Juan Bautista Vázquez el Viejo en Castilla y América, (Madrid: CSIC, 1990).

Estella Marcos 1990: Margarita Estella Marcos, "Sobre escultura española en América y Filipinas y algunos otros temas", en Relaciones artísticas entre España y América, (Madrid: CSIC, 1990), pp. 73-106.

Fajardo 2006: José del Rey Fajardo, Los jesuitas en Venezuela, t. II, Los hombres, (Caracas-Bogotá: Universidad Católica Andrés Bello-Pontifica Universidad Javeriana, 2006).

Felices de la Fuente 2012: María del Mar Felices de la Fuente, La nueva nobleza titulada de España y América en el siglo XVIII (1701-1746): entre el mérito y la venalidad, (Almería: Universidad de Almería, 2012).

Fraga González 1982: Carmen Fraga González, "Santa Bárbara de Icod y el arte de Duque Cornejo", Boletín de Bellas Artes, 10, (1982), pp. 197-208.

Galán García 1995: Agustín Galán García, El "Oficio de Indias" de Sevilla y la organización económica y misional de la Compañía de Jesús (15661767), (Sevilla: Fundación Fondo de Cultura de Sevilla, 1995).

García Luque 2015: Manuel García Luque, "Duque Cornejo, el último barroco", Ars Magazine, 28, (2015), pp. 110-121.

García Luque 2018: Manuel García Luque, "Dibujos de Duque Cornejo en el Álbum Jaffe (II): la colección del Hood Museum of Art", Philostrato. Revista de Historia y Arte, 4, (2018), pp. 33-61.

García Luque 2018: Manuel García Luque, Pedro Duque Cornejo: estudio de su vida y obra (1678-1757), tesis doctoral inédita, Universidad de Granada, (Granada: 2018).

Gila Medina y Herrera García 2010: Lázaro Gila Medina y Francisco J. Herrera García, "Escultores y esculturas en el Reino de la Nueva Granada (Colombia)", en La escultura del primer Naturalismo en Andalucía e Hispanoamérica (1580-1625), dir. Lázaro Gila Medina, (Madrid: Arco/Libros, 2010), pp. 501-562.

Harth-Terré 1962: E. Harth-Terré, "Una escultura de Martínez Montañés en Lima", Cuadernos Hispanoamericanos, 152-153, (1962), pp. 261-271.

Hernández Díaz 1983: José Hernández Díaz, Pedro Duque Cornejo y Roldán (1678-1757), (Sevilla: Diputación Provincial, 1983). 
Herrera García 2018: Francisco J. Herrera García, "Pedro Laboria y la teatralidad elocuente en la escultura barroca bogotana", en El triunfo del barroco en la escultura andaluza e hispanoamericana, coord. Lázaro Gila Medina y F. J. Herrera García, (Granada: Universidad de Granada, 2018), pp. 507-536.

Larrea 2018: Gregorio César de Larrea, "Más datos sobre los Larrea", Boletín de la Academia Nacional de Historia, 199, (2018), pp. 435-367.

Marco Dorta 1979: Enrique Marco Dorta, "Esculturas sevillanas en Colombia y Venezuela", Archivo Español de Arte, 206, (1979), pp. 170-173.

Ortiz Toro 2016: Raúl Ortiz Toro, Los templos históricos de Popayán, (Cali: Arquidiócesis de Popayán, 2016).

Palomero Páramo 2007: Jesús M. Palomero Páramo, "El mercado escultórico entre Sevilla y Nueva España durante el primer cuarto del siglo XVII. Marchantes de la carrera de Indias, obras de plomo exportadas y ensambladores de retablos que pasan a México", en Escultura. Museo Nacional del Virreinato, coords. M. Fernández Félix y M. Montiel Figueiras, vol. 1, (México: Museo Nacional del Virreinato, 2007), pp. 107-118.

Pantoja Barco 2008: Rosita Andrea Pantoja Barco, Afrodita Barroca. Fragmentos para el estudio de una sensibilidad de la cultura. Popayán, siglos XVII y XVIII, (Quito: Ediciones Abya-Yala, 2008).

Quintana Echeverria 2000: Iván Antonio Quintana Echeverría, "Notas sobre el comercio artístico entre Sevilla y América en 1586", Anales del Museo de América, 8, (2000), pp. 103-110.

Ravé Prieto 2018: Juan Luis Ravé Prieto, San Luis de los Franceses, (Sevilla: Diputación Provincial, 2018).

Respeto Martín 1946: Enrique Respeto Martín, Artífices gaditanos del siglo XVII, Col. Documentos para la historia del Arte en Andalucía, t. X, (Sevilla: Universidad de Sevilla-Laboratorio de Arte, 1946).

Sánchez Sánchez 2013: José María Sánchez Sánchez, "Los obradores artísticos sevillanos del siglo XVI: adaptaciones y cambios para satisfacer los encargos del mercado americano", Anales del Instituto de Investigaciones Estéticas, 103, (2013), pp. 177-196.

Sancho Corbacho 1934: Heliodoro Sancho Corbacho, Arquitectura sevillana del siglo XVIII, (Sevilla: Laboratorio de Arte, 1934).

Sebastián 1965: Santiago Sebastián, Arquitectura Colonial en Popayán y Valle del Cauca, (Cali: Biblioteca de la Universidad del Valle, 1965).

Sebastián 1965: Santiago Sebastián, Itinerarios artísticos de la Nueva Granada, (Popayán: Academia de Historia del Valle del Cauca, 1965). 
Taylor 1982: René Taylor, El entallador e imaginero sevillano Pedro Duque Cornejo, 1678-1757, (Madrid: Instituto de España, 1982).

Tulcán 1946: Clemente de Tulcán, Crónica de la fundación del Monasterio de las RR. MM. Carmelitas de Ibarra, (Ibarra: Talleres Tipográficos Municipales, 1946).

Vargas Jurado 1902: José Antonio Vargas Jurado, La Patria Boba: tiempos coloniales, (Bogotá: Academia Colombiana de Historia, 1902).

Recibido: $14 / 10 / 2021$

Aceptado: $27 / 10 / 2021$ 